\title{
A 94-bp Deletion of Anthocyanidin Synthase Gene in Acyanic Flower Lines of Lisianthus [Eustoma grandiflorum (Raf.) Shinn.]
}

\author{
Keiichi Shimizu $^{1}$, Nanako Ohnishi ${ }^{1}$, Noriyuki Morikawa ${ }^{1}$, Ai Ishigami ${ }^{1}$, Saeko Otake ${ }^{1}$, \\ Isselmou Ould Rabah ${ }^{2}$, Yusuke Sakata ${ }^{1}$ and Fumio Hashimoto ${ }^{1,2 *}$ \\ ${ }^{1}$ Faculty of Agriculture, Kagoshima University, Korimoto 1-21-24, Kagoshima 890-0065, Japan \\ ${ }^{2} J S T$ (Japan Science and Technology Agency) Innovation Satellite Miyazaki, Miyazaki 880-0805, Japan
}

\begin{abstract}
We studied the genomic sequence of the anthocyanidin synthase (ANS) gene in acyanic flower lines of lisianthus and detected a 94-bp deletion of the sequence in comparison with that of cyanic flower lines. Cross-pollination was made between acyanic and cyanic flower lines to yield $F_{1}$ progeny, followed by its self-pollination. The segregated individuals between cyanic and acyanic flowers among the $F_{2}$ population were of 24 and 8 , respectively $(3: 1)$, which suggested that one gene of the $F_{1}$ hybrid was unequivocally involved in anthocyanin production. The homozygous $A N S$ genes that have a set of 94-bp deletion co-segregated a recessive phenotype of white color in the $F_{2}$ population. Genomic PCR of the $A N S$ genes of the 14 independent lisianthus lines of acyanic flowers, such as white, yellow, pale yellow, and pale green flowers, revealed that all possessed a homozygous 94-bp deletion. The data support that the acyanic flower colors are associated with a 94-bp deletion in the $A N S$ gene as a result of the loss of anthocyanin accumulation.
\end{abstract}

Key Words: anthocyanidin synthase, anthocyanin, Eustoma grandiflorum, flower color, mutation.

\section{Introduction}

Flower color is the most outstanding and important trait for floricultural plants. The most abundant flavonoid pigments are anthocyanins (Schwinn and Davies, 2004). The anthocyanin biosynthetic pathway has been well characterized biochemically. Nearly all of the structural genes that encode the enzymes engaged in this pathway have been identified in species including Petunia hybrida, Antirrhinum majus, Arabidopsis thaliana (Holton and Cornish, 1995), Ipomoea nil (Morita et al., 2006), and Gentiana triflora (Nakatsuka et al., 2006, 2008; Nishihara et al., 2008).

Anthocyanidin synthase (ANS) catalyzes the biosynthesis of anthocyanidin from the colorless leucoanthocyanidin. The cDNAs and genomic DNA sequence that encode ANS have been isolated from several plant species (Martin et al., 1991; Menssen et al., 1990;

Received; November 1, 2010. Accepted; March 24, 2011.

Part of this paper was presented at the 2009 Autumn Meeting of the Japanese Society for Horticultural Science.

This study was supported by Ikusei Advanced Research Program from the JST Innovation Satellite Miyazaki.

* Corresponding author (E-mail: omihsahf@agri.kagoshima-u.ac.jp).
Nakajima et al., 2000, 2001; Pelletier et al., 1997; Rosati et al., 1999; Saito et al., 1999; Sparvoli et al., 1994; Weiss et al., 1993). Evidence for the involvement of ANS in this catalytic stage was reported by Menssen et al. (1990), who introduced the cDNA encoding maize ANS to a tissue of ANS2 mutant maize by microprojectile bombardment; anthocyanin production was rescued through transient expression. An amino acid homology search revealed that the ANS proteins belong to the class of 2-oxoglutarate-dependent dioxygenases (De Carolis and De Luca, 1994; Prescott and John, 1996).

Lisianthus is one of the most popular cut flowers in Japan due to its large flower, long stem, and extended vase life (Oren-Shamir et al., 1999; Shimizu-Yumoto and Ichimura, 2010). The typical wild-type lisianthus plant has a purple flower, mainly due to its anthocyanin pigments. Cultivars with various flower colors, such as white, pale yellow, pale green, pink, red, and magenta, have been produced by commercial breeding, particularly in Japan (Ledger et al., 1997). Although the ANS gene of lisianthus was cloned by Noda et al. (2004), its relationship with flower color variation is not clear. In this study, we examined the genomic sequences of the $A N S$ gene in lisianthus to elucidate the cause of the acyanic flower. We report that the 94-bp deletion in the 
ANS gene is closely related to the acyanic flower phenotype in lisianthus used in this study.

\section{Materials and Methods}

\section{Plant Materials}

Flower colors and the origins of the lisianthus lines used in this study are listed in Table 1. Seeds of lisianthus 'Mellow Lavender' and 'Royal Violet' were obtained from Takii Seed Co., Ltd. (Japan). Seeds of 'Bridal Violet', 'King of Snow', 'King of Yellow', 'Acropolis White', 'Asuka no Maihime', 'Asuka no Soyokaze', 'Rosina Green', 'Rosina Yellow', 'Cute Green', 'Cute Yellow', 'Asuka White', 'Piccolo Yellow', 'Tsukushi no Shinsetsu', and 'Exrosa Green' were obtained from Sakata Seed Co., Ltd. (Japan). Seeds of 'White Sum' were obtained from Fukukaen Co., Ltd. (Japan). Seeds of 'Spica White' were obtained from Mikado Seed Growers Co., Ltd. (Japan). Seeds of 'Aloha Snow' and 'Summer Purple Rose' were obtained from Murakami Seed Co., Ltd. (Japan). Seeds of 'Papillon Rose Pink' were obtained from Miyoshi Co., Ltd. (Japan). Seeds of 'Mickey Rose' were obtained from Daiichi Engei Co., Ltd. (Japan). 'TR' is a red flower line, which was bred from open pollinated lines at Kagoshima University Experimental Farm. Wild-type lisianthus was sampled in Texas, USA. Seedlings of the cultivars and their different self- and cross-pollinated progenies were transplanted 110 days after sowing to a polyethylene house at Kagoshima University Experimental Farm under standard conditions as previously described (Hashimoto et al., 2004; Uddin et al., 2002).

Young leaves were used for DNA and RNA extraction and petals except the throat were used for RNA extraction at six stages of development: 1 , buds less than $20 \mathrm{~mm}$ long; 2, buds between $20 \mathrm{~mm}$ and $30 \mathrm{~mm}$; 3 , buds more than $30 \mathrm{~mm}$ and tightly closed; 4 , buds more than $30 \mathrm{~mm}$ and loosely closed; 5, opening flowers; and 6, fully opened flowers. For RT-PCR, the cDNAs derived from these six stages were mixed equally. Young leaf and petal samples were immediately frozen in liquid nitrogen and kept at $-80^{\circ} \mathrm{C}$ until DNA and RNA extraction.

\section{CIELab color notation}

Cyanic line 'AM' (self-pollinated line derived from the cultivar 'Asuka no Maihime'), acyanic line 'KS' (self-pollinated line derived from the cultivar 'King of Snow'), and 31 individuals in $F_{2}$ population generated from the cross between them were used for evaluation of flower color. Fully opened flowers were harvested

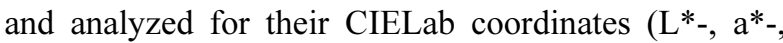
and $b^{*}$-values) with a NR-3000 color analyzer (Nippon Denshoku, Japan). The $\mathrm{C}^{*}$-value was calculated from

Table 1. Flower color and origins of lisianthus lines used in this study.

\begin{tabular}{|c|c|c|}
\hline Name of line & Flower color & Origin \\
\hline 'ME’ & Mauve & Self-pollinated line derived from cultivar 'Mellow Lavender' $\left(\mathrm{F}_{1}\right)$ \\
\hline 'AM' & Pink & Self-pollinated line derived from cultivar 'Asuka no Maihime' $\left(\mathrm{F}_{1}\right)$ \\
\hline 'MR' & Pink & Self-pollinated line derived from cultivar 'Mickey Rose' $\left(\mathrm{F}_{1}\right)$ \\
\hline 'BV' & Violet & Self-pollinated line derived from cultivar 'Bridal Violet' $\left(\mathrm{F}_{1}\right)$ \\
\hline 'RV' & Violet & Self-pollinated line derived from cultivar 'Royal Violet' $\left(\mathrm{F}_{1}\right)$ \\
\hline 'AW' & White & Self-pollinated line derived from cultivar 'Acropolis White' $\left(\mathrm{F}_{1}\right)$ \\
\hline 'KS' & White & Self-pollinated line derived from cultivar 'King of Snow' $\left(\mathrm{F}_{1}\right)$ \\
\hline 'TR' & Red & Open-pollinated line derived from Kagoshima University \\
\hline 'Cute Green’ & Pale green & $F_{1}$ cultivar from seed company \\
\hline 'Exrosa Green' & Pale green & $\mathrm{F}_{1}$ cultivar from seed company \\
\hline 'Rosina Green' & Pale green & $F_{1}$ cultivar from seed company \\
\hline 'Cute Yellow' & Pale yellow & $F_{1}$ cultivar from seed company \\
\hline 'King of Yellow' & Pale yellow & $\mathrm{F}_{1}$ cultivar from seed company \\
\hline 'Piccolo Yellow' & Pale yellow & $\mathrm{F}_{1}$ cultivar from seed company \\
\hline 'Asuka no Maihime' & Pink & $F_{1}$ cultivar from seed company \\
\hline 'Papillon Rose Pink' & Pink & $\mathrm{F}_{1}$ cultivar from seed company \\
\hline 'Summer Purple Rose' & Red-violet & $\mathrm{F}_{1}$ cultivar from seed company \\
\hline 'Asuka no Soyokaze' & Violet & $\mathrm{F}_{1}$ cultivar from seed company \\
\hline 'Aloha Snow' & White & $F_{1}$ cultivar from seed company \\
\hline 'Asuka White' & White & $\mathrm{F}_{1}$ cultivar from seed company \\
\hline 'King of Snow' & White & $F_{1}$ cultivar from seed company \\
\hline 'Tsukushi no Shinsetsu' & White & $\mathrm{F}_{1}$ cultivar from seed company \\
\hline 'White Sum' & White & $\mathrm{F}_{1}$ cultivar from seed company \\
\hline 'Rosina Yellow' & Yellow & $\mathrm{F}_{1}$ cultivar from seed company \\
\hline 'Spica White’ & White & True bred cultivar from seed company \\
\hline 'WT' & Violet & Wild-type lisianthus derived from Texas, USA \\
\hline
\end{tabular}


the equation: $\mathrm{C}^{*}=$ square root of $\left(\mathrm{a}^{* 2}+\mathrm{b}^{* 2}\right)$, and the hue angle was calculated as $\mathrm{h}$ degrees $=\tan ^{-1}\left(\mathrm{~b}^{*} / \mathrm{a}^{*}\right)(\mathrm{CIE}$, 1986).

\section{Characterization of anthocyanidin composition}

Cyanic line 'AM', acyanic line ' $\mathrm{KS}$ ', 31 individuals in the $F_{2}$ population generated from the cross between them, and 8 additional acyanic lines were used for characterization of anthocyanidin composition. Highperformance liquid chromatography (HPLC) using previously described procedures (Hashimoto et al., 2002; Uddin et al., 2001, 2002) was conducted with some modifications. Flower petals except for the throat were harvested at the fully opened stage and stored at $-80^{\circ} \mathrm{C}$ until use. For anthocyanidin analysis, the frozen petal samples were ground into a fine powder in liquid nitrogen and then extracted with $1 \mathrm{~N} \mathrm{HCl}$. The soluble fraction was obtained by centrifugation at $10,000 \mathrm{rpm}$ for $10 \mathrm{~min}$. To obtain the aglycones of anthocyanins, the extracts were hydrolyzed with $2 \mathrm{~N} \mathrm{HCl}$ at $100^{\circ} \mathrm{C}$ for $120 \mathrm{~min}$. The hydrolysates were evaporated and re-dissolved in $2 \mathrm{~mL}$ of $1 \% \mathrm{HCl}$ in $\mathrm{MeOH}$. The samples were passed through a $0.45-\mu \mathrm{m}$ filter and analyzed by HPLC.

Samples were analyzed on a TSK-GEL ODS-80Ts QA column $(4.6 \mathrm{~mm}$ i.d. $\times 150 \mathrm{~mm}$, Tosoh, Japan). The column was attached to a Jasco HPLC system (Jusco Co., Japan) equipped with a gradient pump (PU-2089), mixer (MX-2082-32), autosampler (AS-2051), diode array PDA HPLC detector (MD-2010), and column oven (CO-2060). For analytical scale, the mobile phase consisted of solvent A (1.5\% phosphoric acid and 20\% formic acid) and solvent B (1.5\% phosphoric acid, 20\% formic acid, $25 \%$ acetonitrile, and 5\% tetrahydrofuran). The mobile phase composition was varied by computer from $100 \%$ solvent A to $30 \%$ solvent A and $70 \%$ solvent $\mathrm{B}$ over $30 \mathrm{~min}$. The flow rate was $1 \mathrm{~mL} \cdot \mathrm{min}^{-1}$ and detection was carried out at $525 \mathrm{~nm}$. The total area under the peaks at $525 \mathrm{~nm}$ was converted to a quantity using the calibration curves of anthocyanidin standards.

\section{$R N A$ extraction and RT-PCR}

Six lisianthus lines of 3 cyanic and 3 acyanic lines were used for RT-PCR. Total RNA was extracted from $100 \mathrm{mg}$ petals using the Plant Total RNA Extraction Miniprep System (Viogene, Taiwan) according to the manufacturer's instructions. First-strand cDNA was synthesized from DNase I-treated RNA according to the manufacturer's protocol using the PrimeScript ${ }^{\circledR}$ FirstStrand cDNA Synthesis Kit (Takara Bio Inc., Japan). All PCR primers for the anthocyanin biosynthetic gene were designed from the lisianthus cDNA sequences (Noda et al., 2004) and are shown in Table 2. Each reaction $(20 \mu \mathrm{L})$ consisted of 1x Ex Taq Buffer, $0.2 \mathrm{mM}$ of each dNTP, 0.5 units of Ex Taq ${ }^{\mathrm{TM}}$ HS (Takara Bio), $0.5 \mu \mathrm{M}$ forward primer, and $0.5 \mu \mathrm{L}$ first-strand cDNA as the template. The thermal cycling conditions were $94^{\circ} \mathrm{C}$ for $60 \mathrm{~s}$, followed by $25-30$ cycles of $94^{\circ} \mathrm{C}$ for $30 \mathrm{~s}, 60^{\circ} \mathrm{C}$ for $30 \mathrm{~s}, 72^{\circ} \mathrm{C}$ for $90 \mathrm{~s}$, and a final step of $7 \mathrm{~min}$ at $72^{\circ} \mathrm{C}$. Lisianthus ubiquitin (GenBank accession number AB049409) (Oka et al., 2001) was also amplified by RT-PCR as an internal control using forward (EgUbiF, 5'-ATCCAGTGACACCATCGACA-3') and reverse (EgUbi-R, 5'-TGTTGTAGTCGGCGAGAGTG-3') primers.

\section{Cloning and sequencing}

To sequence the coding region (including intron) of the ANS gene in genomic DNA, cyanic line 'AM' and acyanic line ' $\mathrm{KS}$ ' were used. Genomic DNA was extracted from young lisianthus leaves using the Plant Genomic DNA Extraction Miniprep System (Viogene) according to the manufacturer's instructions. For cloning and sequencing, genomic DNA fragments covering the coding region and intron of the $A N S$ gene were amplified by PCR. Primers (5'-GGCCGCATTCTTACCAAGAT3') and 5'-TCAGAAACATGGACGAACTCC-3') were designed from lisianthus ANS cDNA sequences (AB078957) (Noda et al., 2004). Amplified products were purified and sequenced directly. All sequencing was performed using an ABI PRISM ${ }^{\circledR} 3100$ Genetic Analyzer (Applied Biosystems, USA). The DNA sequence and deduced amino acid sequence analysis and multiple sequence alignments were conducted using the GENETYX program (GENETYX Co., Japan).

Molecular phylogenetic analysis of intron sequence in 9 cyanic lines and 11 acyanic lines based on Clustal W (Thompson et al., 1994) was carried out by the neighbor-joining method (Saitou and Nei, 1987).

Genotyping of the anthocyanidin synthase (ANS) gene in lisianthus

The following materials were used for genotyping of the $A N S$ gene; 32 individuals in $\mathrm{F}_{2}$ population generated

Table 2. Specific primers used for RT-PCR amplification of genes encoding the enzyme involved in the anthocyanin biosynthesis pathway in lisianthus.

\begin{tabular}{lll}
\hline \hline \multirow{2}{*}{ Target } & \multicolumn{2}{c}{ Primer sequences (5' to 3') } \\
\cline { 2 - 3 } & Forward & Reverse \\
\hline CHS & AGAGGTGAGAAGGGCTCAAAG & CGAGACACTGTGTAGAACCACTG \\
$C H I$ & TTCCTCCACTCCTTCCCTTT & ATTCGGGTTGCCAAACTCTT \\
$F 3 H$ & TGGCTCCATCTACACTAACAGC & GATCTCCTCAATAGGCTTGCTC \\
$D F R$ & CCCTGAAAGCCTGTAAGAGC & TACGTGTCCTTGCCATGTTC \\
$A N S$ & CCCCAGAGTAGAAAGCTTGG & TCCTGAAGAGCTTGTGCTTG \\
\hline
\end{tabular}


from the cross between a cyanic line 'AM' and an acyanic line 'KS'; 14 lisianthus lines with acyanic flower; 10 lisianthus lines with cyanic flower. Genomic DNA fragments containing the ANS gene were amplified by PCR. The forward (5'-TGGATCACAGCCAAATGTGT3') and reverse (5'-TGGTTGAATCCATGTCTTTTG-3') primers were designed from lisianthus ANS cDNA sequences (GenBank accession number AB078957) (Noda et al., 2004). These primers were sited on both sides of $94 \mathrm{bp}$ deletion in the $A N S$ gene (Fig. 3). The composition of reaction mixtures $(20 \mu \mathrm{L})$ was the same as RT-PCR except for a template of approximately $25 \mathrm{ng}$ DNA. The thermal cycling conditions were $94^{\circ} \mathrm{C}$ for $60 \mathrm{~s}$, followed by 30 cycles of $94^{\circ} \mathrm{C}$ for $30 \mathrm{~s}, 60^{\circ} \mathrm{C}$ for $30 \mathrm{~s}$, and $72^{\circ} \mathrm{C}$ for $30-60 \mathrm{~s}$, and then a final step of $1-$ $4 \mathrm{~min}$ at $72^{\circ} \mathrm{C}$.

\section{Results}

Analysis of the color segregation ratio in the $F_{2}$ population and HPLC

The lisianthus cyanic flower line 'AM' exhibits a pink flower due to the loss of flavonoid 3',5'-hydroxylase (F3'5'H) activity (data not shown). The acyanic line ' $\mathrm{KS}$ ' produces a white flower and also has the same mutation in the $F 3^{\prime} 5^{\prime} H$ gene as 'AM' (data not shown). The $\mathrm{F}_{1}$ 'KS' $\times$ 'AM' hybrid displays a pink flower, and was selfpollinated to produce an $\mathrm{F}_{2}$ segregating population. The colors of the $\mathrm{F}_{2}$ population segregated into 24 pink and 8 white flower plants with $L^{*}$-values of $65.4 \pm 7.3$ in the 24 pink flowers and $93.7 \pm 0.2$ in the 7 white flowers (Table 3) (one white flower plant had withered before sampling). This segregation ratio fits well with the expected 3:1 ratio of Mendelian inheritance. L*-values in the parental plants of 'AM' and 'KS' exhibit 31.6 and 91.6, respectively, and ranged from 44.3 to 76.5 in the cyanic flower in $\mathrm{F}_{2}$ populations, whereas 93.5 to 94.0 in acyanic flowers (Fig. 1). Subtle color variation was observed between pink flower individuals in $F_{2}$ population by visual assessment.

HPLC analysis of the 24 pink flower petals showed an average anthocyanidin accumulation of $131.8 \pm$ $65.5 \mu \mathrm{g} \cdot \mathrm{g}^{-1}$, whereas $4.5 \pm 0.4 \mu \mathrm{g} \cdot \mathrm{g}^{-1}$ anthocyanidin was detected in 7 of the 8 white flowers (one acyanic flower plant had withered before sampling for HPLC). The anthocyanidin accumulation was $777.7 \mu \mathrm{g} \cdot \mathrm{g}^{-1}$ in the 'AM' parent plants and was not detected in ' $\mathrm{KS}$ '. The anthocyanidin accumulation in the petals of cyanic individuals ranged from 46.3 to $264.8 \mu \mathrm{g} \cdot \mathrm{g}^{-1}$, whereas acyanic flowers ranged from 3.9 to $4.9 \mu \mathrm{g} \cdot \mathrm{g}^{-1}$ (Fig. 1). Average accumulation of anthocyanidin in cyanic individuals of $\mathrm{F}_{2}$ population is lower than in cyanic parent 'AM' and no $\mathrm{F}_{2}$ individual is equal to 'AM' (Fig. 1). HPLC analysis was also performed on 8 other lisianthus acyanic lines, and a small amount of anthocyanidin was detected in four lines: 'Acropolis White' $\left(5.1 \mu \mathrm{g} \cdot \mathrm{g}^{-1}\right)$, 'Rosina Green' $\left(6.6 \mu \mathrm{g} \cdot \mathrm{g}^{-1}\right)$, 'Cute Green' $\left(4.1 \mu \mathrm{g} \cdot \mathrm{g}^{-1}\right)$, and 'King of Yellow' $\left(0.8 \mu \mathrm{g} \cdot \mathrm{g}^{-1}\right)$; however, anthocyanidin was not detected in four lines: 'King of Snow' (origin of 'KS'), 'Tsukushi no Shinsetsu', 'Spica White', and 'Asuka White'.

Gene expression of enzymes for anthocyanin biosynthesis

The gene expression of the enzymes responsible for anthocyanin biosynthesis in petals was investigated by RT-PCR using specific primers (Table 2). Primers were designed from previously reported lisianthus flavonoid biosynthetic genes (Noda et al., 2004). In the 30 cycles, all of the amplification products for CHS (chalcone synthase) gene, CHI (chalcone isomerase) gene, F3H

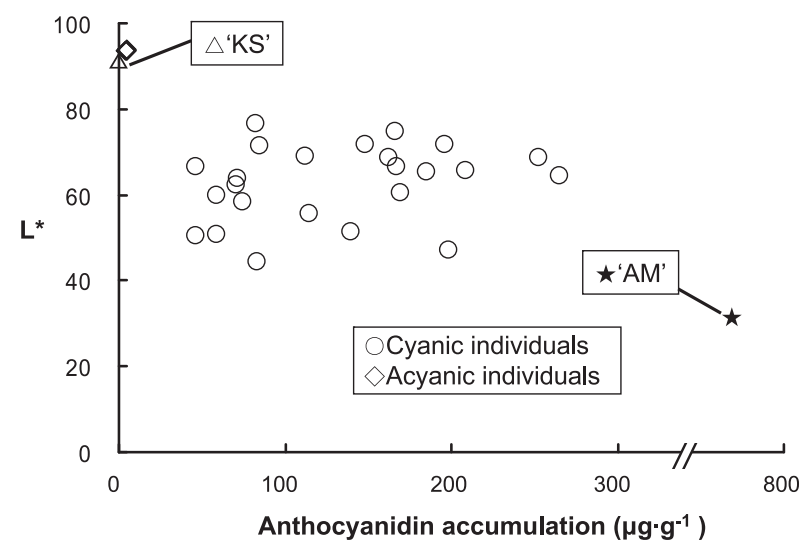

Fig. 1. Correlation of anthocyanidin accumulation and petal colors in the $\mathrm{F}_{2}$ population generated from the cross between a cyanic line 'AM' and an acyanic line 'KS'. The anthocyanidin amount in the petals of individual $\mathrm{F}_{2}$ plants was plotted against the flower color represented by the $\mathrm{L}^{*}$-value.

Table 3. Flower color attributes and anthocyanidin accumulation in the acyanic 'KS' and cyanic 'AM' lines as well as $\mathrm{F}_{2}$ populations from crosses between them.

\begin{tabular}{lcccc}
\hline \hline \multirow{2}{*}{ Line } & $\begin{array}{c}\text { Anthocyanidin } \\
\text { amounts }\left(\mu \mathrm{g} \cdot \mathrm{g}^{-1}\right)\end{array}$ & \multicolumn{3}{c}{ Color coordinates $^{\text {zy }}$} \\
\cline { 3 - 5 } & 777.7 & 80.3 & $\mathrm{~L}^{*}$ & \multicolumn{3}{c}{} \\
\hline 'AM' & 0 & 4.6 & 31.6 & 1.5 \\
'KS' & $131.8 \pm 65.5$ & $53.6 \pm 10.0$ & $65.6 \pm 7.3$ & $-6.2 \pm 1.0$ \\
Cyanic in $\mathrm{F}_{2}$ & $4.5 \pm 0.4$ & $5.6 \pm 0.8$ & $93.7 \pm 0.2$ & $-12.3 \pm 88.2$ \\
Acyanic in $\mathrm{F}_{2}$ & & &
\end{tabular}

${ }^{z}$ Fresh petals were observed.

${ }^{y} \mathrm{~L}^{*}$, lightness; $\mathrm{C}^{*}$, chroma (brightness); $h$, hue angle (degree, ${ }^{\circ}$ ).

Data are the mean \pm SD (7 samples in acyanic individuals and 24 samples in cyanic individuals). 
(flavanone 3-hydroxylase) gene, DFR (Dihydroflavonol 4-reductase) gene, and ANS gene were detected in the cyanic flower lines 'RV' (self-pollinated line derived from cultivar 'Royal Violet'), 'ME' (self-pollinated line derived from cultivar 'Mellow Lavender'), and 'AM'. By contrast, the product corresponding to the ANS gene was not amplified from the acyanic flower lines 'KS', 'AW' (derived from 'Acropolis White'), and 'Tsukushi no Shinsetsu' (Fig. 2). First, we deduced that these differences were caused by the loss of ANS gene expression; however, when the reverse primer for the ANS gene was changed, we could amplify fragments of the ANS gene (data not shown); therefore, we hypothesized that the genomic region corresponding to the reverse primer might have mutated. In the 25 cycles, amplification products of $C H S$ in 'KS' and 'Tsukushi no Shinsetsu', and $C H I$ in 'RV', 'AM' and 'KS' were fewer than those of others. On the other hand, loss of amplification products in the ANS gene was distinct in acyanic flowers.

\section{Sequence analyses of the ANS gene}

The coding region and intron of the ANS genes in the lisianthus genome were sequenced and compared with the previously reported cDNA sequence of the lisianthus ANS gene (Noda et al., 2004). Two exons and one intron were identified, and some base substitutions were present between the known cDNA sequence and the genomic sequence of the $A N S$ gene in this study (Fig. 3). The exons of the $A N S$ gene in 'AM' and the previously

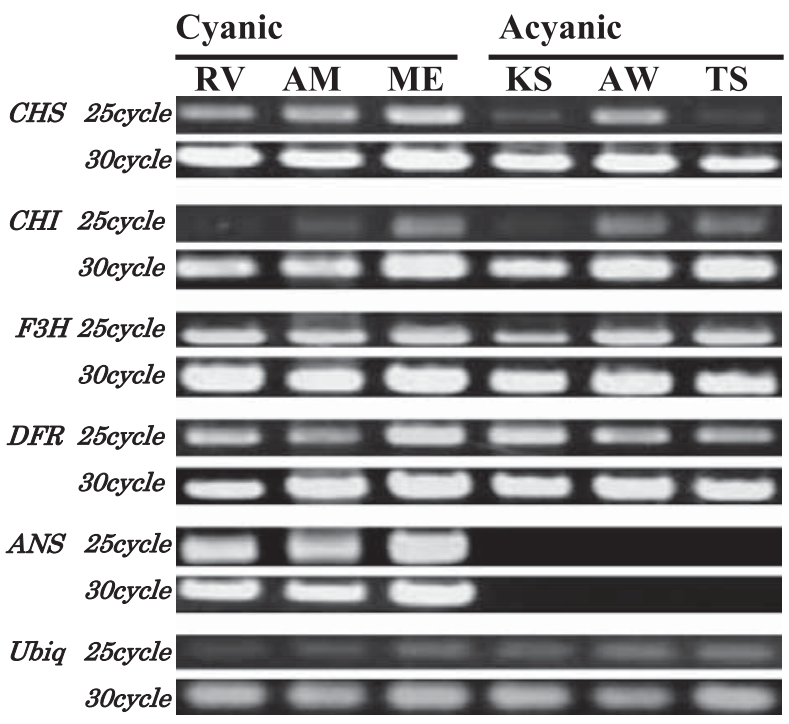

Fig. 2. RT-PCR analysis of anthocyanin biosynthesis genes in cyanic and acyanic lines in lisianthus. RV, 'RV' derived from 'Royal Violet'; AM, 'AM' derived from 'Asuka no Maihime'; ME, 'ME' derived form 'Mellow Lavender'; KS, 'KS' derived from 'King of Snow'; AW, 'AW' derived from 'Acropolis White'; TS, 'Tsukushi no Shinsetsu'. CHS, chalcone synthase gene; $C H I$, chalcone isomerase gene; $F 3 H$, flavanone 3-hydroxylase gene; $D F R$, dihydroflavonol 4-reductase gene; $A N S$, anthocyanidin synthase gene; Ubiq, Lisianthus ubiquitin gene. reported $A N S$ gene showed 99\% DNA sequence identity and differed by only 1 nucleotide substitutions. These nucleotide differences led to differences in the corresponding amino acid sequences at one position (214), and amino acid sequence identity was $99 \%$. The positions of these amino acid differences were not within the conserved regions of the ANS enzyme.

By comparing the exons of the ANS gene in 'KS' with the previously reported $A N S$ gene, we detected a 94-bp deletion (Fig. 4A) in the second exon and 14 nucleotide substitutions. The nucleotide substitutions led to changes in the corresponding amino acid sequences at 5 positions: 58, 66, 69, 214, and 323 (Fig. 4B), but the positions of

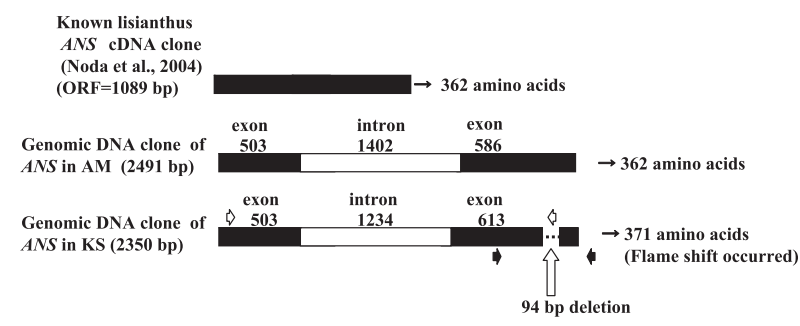

Fig. 3. Diagram showing the structure of the ANS cDNA clone (AB078957) (Noda et al., 2004) in known lisianthus, the genomic DNA clone of ANS gene in cyanic flower line 'AM' (AB551412), and the acyanic flower line 'KS' (AB551408). These genes in diagram do not contain 5'- and 3'-untranslational region. Black arrows of ' $\mathrm{KS}$ ' indicate the position of the genotyping primers for detection of deletion in Figures 6 and 7. Reverse primer for genotyping is located at the 3 '-untranslational region of $A N S$ gene. White arrows indicate the position of the ANS gene primers for RT-PCR in Figure 2. Numbers indicate the sizes (bp) of the exons and introns.

A

Eustoma CDNA 988 ATCGTCCTCAAGCCACTACCTGAGACTGTGTCTGAATCCGAGCCGGCTCG 1037 Cyanic gDNA 2342 ATCGTCCTCAAGCCACTACCTGAGACTGTGTCTGAATCCGAGCCGGCTCG 239 Acyanic gDNA 2174 ATCGTCCTCAAGCCACTACCTGAGACTCTGTCTGAAT--:--:------ 2210 Eustoma CDNA 1038 GTTCCCTCCTCGCACGTTTGCTGAGCATATCAAGCACAAGCTCTTCAGGA 1087 Cyanic gDNA 2392 GTTCCCTCCTCGCACGTTTGCTGAGCATATCAAGCACAAGCTCTTCAGGA 2441 Acyanic gDNA 2210 Eustoma CDNA 1088 AAAGTGAAGAAACTAATGAAGATAACAATTTACCAAAGGGTAGTTCCTAG 1137 Cyanic gDNA 2442 AAAGTGAAGAAACTAATGAAGATAACAATTTACCAAAGGGTAGTTCCTAG 2491 Acyanic gDNA 2211 - 2229

B

o. Sativa 329 ELLADGAGKPLFAPRTFKQHVQRKLFKKKLKDQDNNAAAAASNGMITK----- 375 A. thaliana 319 EMVSV-ESPAKFPPRTFAQHIEHKLFGKEQEELVSEKND---------- 356 Eustoma 321 ETVSE-SEPARFPPRTFAEHIKHKLERKSEETNEDNINLPKGSS-------- 362 AM 321 ETVSE-SEPARFPPRTFAEHIKHKLERKSEETNEDNNLPKGSS---:--- 362 KS 321 ETLSE-YQRVVPRFVVVCLSQNSLYTWSRNIVADVFRFILFNIYNNYIVNYI 371

Fig. 4. Multiple alignment of $A N S$ genes and amino acid sequences. (A) Multiple alignment of partial ANS cDNA of known lisianthus (Eustoma cDNA) (AB078959), genomic DNA sequences of a cyanic line 'AM' (AB551412), and an acyanic line ' $\mathrm{KS}$ ' (AB551408). Conserved DNA sequences are boxed. Underline indicates the position of the ANS gene reverse primer for RTPCR in Figure 2. (B) Multiple alignment of deduced partial ANS amino acid sequences of Oryza sativa (Y07955), Arabidopsis thaliana (Q96323), known lisianthus (Eustoma) (AB078959), a cyanic line 'AM' (AB551412), and an acyanic line ' $\mathrm{KS}$ ' (AB551408). Conserved amino acids are boxed. Stars indicate substrate-binding residues, based on the results of Wilmouth et al. (2002). 
these amino acid differences were not within the conserved regions of the ANS enzyme. Except for the 94-bp deletion and its downstream sequence, the exons of the ANS gene in 'KS' and of the previously reported ANS gene showed $98 \%$ DNA sequence identity and $98 \%$ amino acid sequence identity. This 94-bp deletion caused marked amino acid changes by a translational frame shift (Fig. 4B). The resulting protein of 371 amino acids lacked some conserved substrate-binding residues (Wilmouth et al., 2002), common to dicotyledonous lisianthus and monocotyledonous rice (Fig. 4B); therefore, the transcripts of the ANS gene in 'KS' might not be translated into the normal ANS enzyme, and this 94bp deletion may contribute to the generation of acyanic flowers in lisianthus used in this study.

The exons of the ANS gene in cyanic 'AM' and acyanic 'KS', with the exception of the 94-bp deletion, showed $98 \%$ DNA sequence identity; however, their introns had $84 \%$ sequence identity and different lengths (1402 bp and $1234 \mathrm{bp}$ for 'AM' and 'KS', respectively). Sequence comparison and phylogenic analysis of the introns of $A N S$ genes in 11 independent acyanic lines and 9 cyanic lines are shown in Figure 5. Although the intron sequences of 9 cyanic lines varied, the sequences of nearly all acyanic lines identical (Fig. 5).

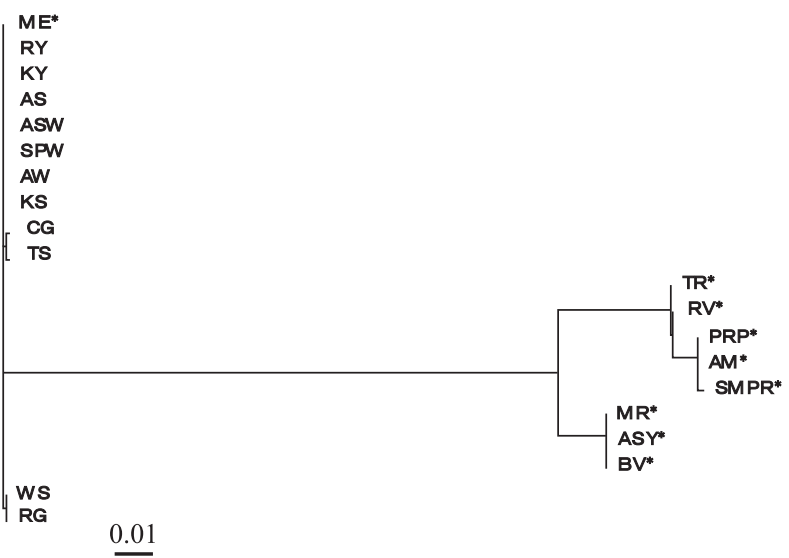

Fig. 5. Sequence comparison and phylogenic analysis of ANS gene introns in 9 cynic and 11 acyanic lisianthus lines. Asterisks indicate cyanic lines. ME, 'ME' derived form 'Mellow Lavender' (AB547147); RY, 'Rosina Yellow' (AB547138); KY, 'King of Yellow' (AB547137); AS, 'Aloha Snow' (AB547136); ASW, 'Asuka White' (AB547135); SPW, 'Spica White' (AB547134); AW, 'AW' derived from 'Acropolis White' (AB547131); KS, 'King of Snow' (AB547130); CG, 'Cute Green' (AB547139); TS, 'Tsukushi no Shinsetsu' (AB547132); TR, 'TR' (AB547148); RV, 'RV' derived from 'Royal Violet' (AB547143); PRP, 'Papillon Rose Pink' (AB547144); AM, 'Asuka no Maihime' (AB547141); SMPR, 'Summer Purple Rose' (AB547149); MR, 'MR' derived from 'Mickey Rose' (AB547142); ASY, 'Asuka no Soyokaze' (AB547145); BV, 'BV' derived form 'Bridal Violet' (AB547146); WS, 'White Sum' (AB547133); RG, 'Rosina Green' (AB547140).
Co-segregation of ANS allele and color phenotype in the $F_{2}$ population

The $\mathrm{F}_{2}$ population of ' $\mathrm{KS}$ ' $\times$ 'AM' was examined for a relationship between the white flower phenotype and $A N S$ genotype (Fig. 6). The presence or absence of the 94-bp deletion was surveyed by genomic PCR using a specific primer pair positioned on both sides of the 94bp deletion. The results revealed co-segregation of the 94-bp deletion with the white flower phenotype in the $\mathrm{F}_{2}$ population (Fig. 6). A normal $A N S$ gene fragment of approximately $500 \mathrm{bp}$ was amplified from anthocyaninaccumulating individuals, whereas only an approximately $400 \mathrm{bp}$ fragment of the 94-bp deleted ANS gene was amplified from acyanic plants. These results were further confirmed by the finding of the same 94-bp deletion in the genomic sequence of 14 additional lisianthus acyanic lines, including lines with white, yellow, pale yellow, and pale green flowers (Fig. 7).

M Cyanic

$500 \mathrm{bp}$

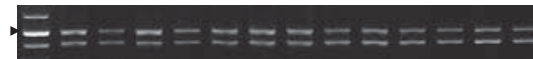

$500 \mathrm{bp}$

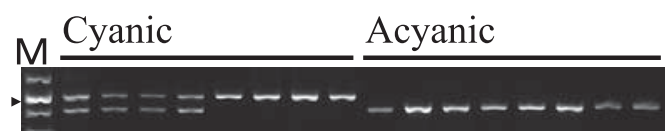

Fig. 6. Co-segregation of a PCR-based marker and the color phenotypes in the $32 \mathrm{~F}_{2}$ population generated from the cross between a cyanic line 'AM' and an acyanic line 'KS'. Lane M, $100 \mathrm{bp}$ DNA size marker and numbers on the left indicate the sizes of DNA markers. One acyanic plant failed HPLC analysis and CIELab color notation.

A

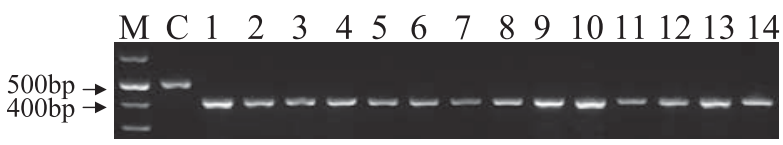

B

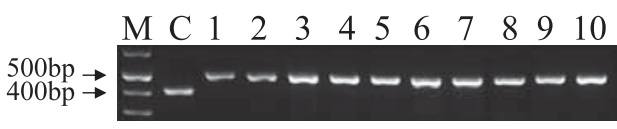

Fig. 7. Genotyping of $A N S$ gene in 14 acyanic (A) and 10 cyanic (B) lisianthus lines using a PCR-based marker. Numbers on the left indicate the sizes of DNA markers. Lane M, $100 \mathrm{bp}$ DNA size marker and numbers on the left indicate the sizes of DNA markers. Lane $\mathrm{C}$ in A, Cyanic control line of 'Asuka no Maihime'. Lane C in B, Acyanic control line of 'King of Snow'. Lane1-14 in A, 'KS' derived from 'King of Snow', 'AW' derived from 'Acropolis White', 'Tsukushi no Shinsetsu', 'White Sum', 'Spica White', 'Asuka White', 'Aloha Snow', 'King of Yellow', 'Rosina Yellow', 'Cute Yellow', 'Piccolo Yellow', 'Cute Green', 'Rosina Green', 'Exrosa Green', respectively. Lane 1-10 in B, 'AM' derived from 'Asuka no Maihime', 'MR' derived from 'Mickey Rose', 'RV' derived from 'Royal Violet', 'Papillon Rose Pink', 'Asuka no Soyokaze', 'BV' derived from 'Bridal Violet', 'ME' derived from 'Mellow Lavender', 'TR' 'Summer Purple Rose', wild-type lisianthus sampled in Texas, USA, respectively. 


\section{Discussion}

In the present study, we demonstrated that mutation of the ANS gene is associated with acyanic flowers in lisianthus, based on the observed co-segregation of the 94-bp deletion mutation in the ANS gene and the color phenotypes in the $\mathrm{F}_{2}$ segregating population. The $\mathrm{C}$ terminal 37 amino acids of ANS in the lisianthus acyanic lines had a completely different sequence due to the 94bp deletion and frame shift. Wilmouth et al. (2002) investigated the crystal structure of ANS from Arabidopsis thaliana, and reported that the $\alpha$-helix in the C-terminal region forms a lid over the active site. Furthermore, this region contains the substrate-binding residues Phe-334, Ile-338, Lys-341, and Leu-342, which correspond to Phe-336, Ile-340, Lys-343, and Leu-344, respectively, in lisianthus ANS. With the exception of Ile-340, these residues are conserved between dicotyledonous lisianthus and monocotyledonous Oryza sativa (Fig. 4B). In the lisianthus acyanic line, these $\alpha$ helix and substrate-binding residues were replaced by different amino acid sequences due to the 94-bp deletion; therefore, the 94-bp deletion includes an important domain for anthocyanidin formation from leucoanthocyanidin.

Several base substitutions also specifically occur in the $A N S$ gene of acyanic lisianthus. The possibility that these base substitutions cause acyanic flowers in lisianthus cannot be excluded; however, this probability is low because they do not occur within the conserved regions of the $A N S$ gene. An alternative mechanism is that another gene closely linked to the 94-bp deletion of ANS gene causes acyanic flowers. To confirm the relationship between the 94-bp deletion and acyanic flowers, the $A N S$ gene needs to be transferred into a acyanic flower line.

Although a comparatively small amount of anthocyanidin was detected in white flowers in the $\mathrm{F}_{2}$ population generated from the cross between ' $\mathrm{KS}$ ' and 'AM', anthocyanidin accumulation was not detected at all in the parental plant of ' $\mathrm{KS}$ '. We investigated 8 lisianthus cultivars with 94-bp deletions; anthocyanidin was detected in four of these lines, but not in four (including the 'King of Snow' origin of the parental plant of ' $\mathrm{KS}$ '). These results suggest that the mutated $A N S$ gene may show weakened function or that another circumventing pathway catalyzes the reaction of leucoanthocyanidin to anthocyanidin. It is likely that leucoanthocyanidin was artificially converted into anthocyanidin by hydroxylation treatment during anthocyanidin elution in this study.

Expression of the CHS gene seems comparatively low in ' $\mathrm{KS}$ ' and 'Tsukushi no Shinsetsu' (Fig. 2). This may be involved in loss of anthocyanidin accumulation in these lines. We show that cyanic individuals in $\mathrm{F}_{2}$ populations between ' $\mathrm{KS}$ ' and 'AM' vary in anthocyanidin accumulation, but no $\mathrm{F}_{2}$ plant reaches anthocya- nidin accumulation one-half of that in the parent cyanic plant 'AM' (Fig. 1). This result may suggest that several factors, such as CHS expression, are involved in the suppression or loss of anthocyanidin accumulation in acyanic flower lines; however, sufficient expression of the CHS gene was detected in some ' $\mathrm{KS}$ ' petals in a preliminary experiment (data not shown), the expression of the CHS gene may depend on environmental conditions.

The acyanic flower is reported to arise from mutations in enzymatic or regulatory genes that confer flavonoid biosynthesis. In the petunia, $A n 1$ and $A n 2$ mutants are caused by a deficiency of a regulatory gene (Quattrocchio et al., 1999; Spelt et al., 2000), while An6 is caused by an impaired DFR gene (Holton and Cornish, 1995; Huits et al., 1994). In A. majus, combinatorial control by three alleles, Delila, Eluta, and Rosea, is known to be involved in the spatial regulation of flower pigmentation, and a nivea mutation affects chalcone synthase (Holton and Cornish, 1995). In Japanese morning glory, $c$ and $c a$ mutations conferring acyanic flowers were frameshift mutations caused by a 2-bp deletion and 7-bp insertions in the genes encoding the R2R3-MYB and WDR transcriptional regulators, respectively (Morita et al., 2006), and $a-3$ and $S p-1$, which cause unstable acyanic flowers, resulted from a transposon insertion in the DFR gene and $C H I$ gene, respectively (Iida et al., 1999).

Davies et al. (1993) analyzed the expression of some anthocyanin biosynthetic genes in the flowers of five lisianthus lines, including two acyanic flower lines. It was reported that $D F R$ gene expression was decreased in one acyanic flower line and that neither of the two acyanic flower lines had ANS activity. This reduction or loss of ANS activity in two acyanic flower lines is in agreement with our results. Noda et al. (2004) analyzed the anthocyanin biosynthetic genes in the acyanic flower cultivar 'Tsukushi no Yuki' by Northern blotting and detected the normal $A N S$ gene transcript, but not the CHS gene. They also conducted RT-PCR and the CHS expression was scarcely detected but the RT-PCR data were not shown.

In our study, all of the acyanic flower lines tested were homozygous for a 94-bp deletion, and expression of the abnormal 94-bp-deleted ANS mRNA was detected by RT-PCR in some acyanic lines (data not shown). 'Tsukushi no Yuki' is no longer available because this cultivar was discontinued, but 'Tsukushi no Shinsetsu', which was improved from 'Tsukushi no Yuki' is now available (Sakata Seed Co., Ltd.). The ANS gene of this cultivar is homozygous for the 94-bp deletion, and comparatively reduced expression of $C H S$ was detected by RT-PCR (Fig. 2). If the $C H S$ gene expression detected was sufficient for chalcone synthesis, the 94-bp-deleted ANS gene may be introduced into 'Tsukushi no Shinsetsu' and mutation of the CHS gene may be eliminated by selection in the process of breeding.

In this study, we surveyed 14 acyanic flower lines in 
lisianthus, but did not observe a normal $A N S$ gene in any of them. Is the 94-bp deletion in the ANS gene the only gene responsible for the white flower phenotype in these lines? The acyanic flower phenotype of 'KS' was confirmed to arise from a single gene mutation, and 'Acropolis White' contains the same single gene mutation in $A N S$, according to our preliminary results (data not shown); however, we cannot exclude the possibility that the other acyanic lines (i.e., not ' $\mathrm{KS}$ ' and 'Acropolis White') have other mutations, e.g., in DFR gene, $\mathrm{CHS}$ gene, and $\mathrm{CHI}$ gene. We also cannot exclude the possibility that weak expression of the CHS gene in 'KS' and 'Tsukushi no Shinsetsu' (Fig. 2) may contribute to acyanic flowers. Even if sufficient mRNAs of these genes were detected, they might be pseudo genes. Genetic experiments are needed to confirm the relationship between the 94-bp deletion in the ANS gene and the white flower phenotype.

With the exception of the 94-bp deletion, the DNA sequences of the exons of the ANS gene were 98\% identical between ' $\mathrm{KS}$ ' and 'AM'; by contrast, the introns significantly differed between the lines. A survey of 20 lisianthus lines revealed that many types of $A N S$ alleles exist in lisianthus. The lengths of the introns in the cyanic lines vary from $1234 \mathrm{bp}-1423 \mathrm{bp}$ with sequence identity of $84 \%-100 \%$. By contrast, the introns of almost all acyanic lines are identical, suggesting that the $A N S$ genes of acyanic lisianthus lines are derived from the same origin or that the 94-bp deletion occurred within the recent evolutionary past. The ANS gene in the cyanic line 'ME' derived from cultivar 'Mellow Lavender' was almost identical to that in acyanic lines (Fig. 5). This suggests that acyanic lines have arisen form 'Mellow Lavender' or a common ancestor.

DNA markers for the anthocyanin biosynthesis related genes have been developed in several plants (Kim et al., 2004; Kobayashi, 2009; Matsubara et al., 2006; Nakajima et al., 2005). Mutations in the $F 3^{\prime} 5^{\prime} H$ and rhamnosyltransferases gene are used as DNA markers of flower color in P. hybrida (Matsubara et al., 2006; Nakajima et al., 2005). DNA markers for bulb color in the onion have been developed using polymorphisms in the ANS and DFR genes (Kim et al., 2004); however, a useful DNA marker for flower breeding in lisianthus, as far as we know, has not been reported. In conclusion, we discovered that a 94-bp deletion co-segregated in the lisianthus acyanic flower line; this deletion may be a reliable and convenient DNA marker for breeding acyanic flowers. Because this marker is co-dominant, it could also be used to distinguish cyanic plants having a heterozygous ANS gene from the segregating population.

\section{Literature Cited}

CIE. 1986. Recommendations on uniform color spaces, color difference equations, psychometric color terms. p. 1-74. In: CIE Central Bureau (ed.). Colormetry (2nd eds.). Publication
No. 15.2. Commission Internationale de l'Éclairage Central Bureau, Vienna.

Davies, K. M., J. M. Bradley, K. E. Schwinn, K. R. Markham and E. Podivinsky. 1993. Flavonoid biosynthesis in flower petals of five lines of lisianthus (Eustoma grandiflorum Grise.). Plant Sci. 95: 67-77.

De Carolis, E. and V. De Luca. 1994. 2-Oxoglutarate-dependent dioxygenase and related enzymes: biochemical characterization. Phytochemistry 36: 1093-1107.

Hashimoto, F., M. Tanaka, H. Maeda, S. Fukuda, K. Shimizu and Y. Sakata. 2002. Changes in flower coloration and sepal anthocyanins of cyanic Delphinium cultivars during flowering. Biosci. Biotechnol. Biochem. 66: 1652-1659.

Hashimoto, F., A. F. M. J. Uddin, K. Shimizu and Y. Sakata. 2004. Multiple allelism in flavonoid hydroxylation in Eustoma grandiflorum (Raf.) Shinn. flowers. J. Japan. Soc. Hort. Sci. 73: $235-240$.

Holton, T. A. and E. C. Cornish. 1995. Genetics and biochemistry of anthocyanin biosynthesis. Plant Cell 7: 1071-1083.

Huits, H. S., A. G. Gerats, M. M. Kreike, J. N. Mol and R. E. Koes. 1994. Genetic control of dihydrofavonol 4-reductase gene expression in Petunia hybrida. Plant J. 6: 295-310.

Iida, S., A. Hoshino, Y. Johzuka-Hisatomi, Y. Habu and Y. Inagaki. 1999. Floricultural traits and transposable elements in the Japanese and common morning glories. Annal. New York Acad. Sci. 870: 265-274.

Kim, S., K. Yoo and L. M. Pike. 2004. Development of a codominant PCR-based marker for an allelic selection of the pink trait in onions (Allium cepa) based on the insertion mutation in the promoter of the anthocyanidin synthase gene. Theor. Appl. Genet. 110: 573-578.

Kobayashi, S. 2009. Regulation of anthocyanin biosynthesis in grapes. J. Japan. Soc. Hort. Sci. 78: 387-393.

Ledger, S. E., S. C. Deroles, D. G. Manson, J. M. Bradley and N. K. Given. 1997. Transformation of lisianthus (Eustoma grandiflorum). Plant Cell Rep. 16: 853-858.

Martin, C., A. Prescott, S. Mackay, J. Bartlett and E. Vrijlandt. 1991. Control of anthocyanin biosynthesis in flowers of Antirrhinum majus. Plant J. 1: 37-49.

Matsubara, K., S. M. Chen, J. X. Lee, H. Kodama, H. Kokubun, H. Watanabe and T. Ando. 2006. PCR-based markers for the genotype identification of flavonoid 3',5'-hydroxylase genes governing floral anthocyanin biosynthesis in commercial petunias. Breed. Sci. 56: 389-397.

Menssen, A., S. Höhmann, W. Martin, P. S. Schnable, P. A. Peterson, H. Saedler and A. Gierl. 1990. The En/Spm transposable element of Zea mays contains splice sites at the termini generating a novel intron from a $d S p m$ element in the A2 gene. EMBO J. 9: 3051-3057.

Morita, Y., M. Saitoh, A. Hoshino, E. Nitasaka and S. Iida. 2006. Isolation of cDNAs for R2R3-MYB, bHLH and WDR transcriptional regulators and identification of $\mathrm{c}$ and $c a$ mutations conferring white flowers in the Japanese morning glory. Plant Cell Physiol. 47: 457-470.

Nakajima, T., K. Matsubara, H. Kodama, H. Kokubun, H. Watanabe and T. Ando. 2005. Insertion and excision of transposable element governs the red floral phenotype in commercial petunias. Theor. Appl. Genet. 110: 1038-1043.

Nakajima, J., Y. Tanaka, M. Yamazaki and K. Saito. 2000. cDNA Cloning and gene expression of anthocyanidin synthase from Torenia fournieri. Plant Biotechnol. 17: 331-335.

Nakajima, J., Y. Tanaka, M. Yamazaki and K. Saito. 2001. Reaction mechanism from leucoanthocyanidin to anthocyanidin 3glucoside, a key reaction for coloring in anthocyanin biosynthesis. J. Biol. Chem. 276: 25797-25803. 
Nakatsuka, T., K. S. Haruta, C. Pitaksutheepong, Y. Abe, Y. Kakizaki, K. Yamamoto, N. Shimada, S. Yamamura and M. Nishihara. 2008. Identification and characterization of R2R3MYB and bHLH transcription factors regulating anthocyanin biosynthesis in gentian flowers. Plant Cell Physiol. 49: 1818 1829.

Nakatsuka T., M. Nishihara, K. Mishiba, H. Hirano and S. Yamamura. 2006. Two different transposable elements inserted in flavonoid 3',5'-hydroxylase gene contribute to pink flower coloration in Gentiana scabra. Mol. Genet. Genomics 275: 231-241.

Nishihara, M., T. Nakatsuka, M. M. Fukuchi, Y. Tanaka and S. Yamamura. 2008. Gentians: From gene cloning to molecular breeding. p. 57-67. In: A. Jaime and T. da Silva (eds.). Floriculture, ornamental and plant biotechnology V. Global Science Books, Middlesex.

Noda, N., Y. Kanno, N. Kato, K. Kazuma and M. Suzuki. 2004. Regulation of gene expression involved in flavonol and anthocyanin biosynthesis during petal development in lisianthus (Eustoma grandiflorum). Physiol. Plant. 122: 305313.

Oka, M., Y. Tasaka, M. Iwabuchi and M. Mino. 2001. Elevated sensitivity to gibberellin by vernalization in the vegetative rosette plants of Eustoma grandiflorum and Arabidopsis thaliana. Plant Sci. 160: 1237-1245.

Oren-Shamir, M., L. Shaked-Sachray, A. Nissim-Levi and R. Ecker. 1999. Anthocyanin pigmentation of lisianthus flower petals. Plant Sci. 140: 99-106.

Pelletier, M. K., J. R. Murrell and B. W. Shirley. 1997. Characterization of flavonol synthase and leucoanthocyanidins dioxygenase genes in Arabidopsis. Plant Physiol. 113: $1437-1445$.

Prescott, A. G. and P. John. 1996. Dioxygenases: molecular structure and role in plant metabolism. Annu. Rev. Plant Physiol. Plant Mol. Biol. 47: 245-271.

Quattrocchio, F., J. Wing, K. van der Woude, E. Souer, N. de Vetten, J. N. Mol and R. Koes. 1999. Molecular analysis of the anthocyanin 2 gene of petunia and its role in the evolution of flower color. Plant Cell 11: 1433-1444.

Rosati, C., A. Cadic, M. Duron, M. Ingouff and P. Simoneau. 1999. Molecular characterization of the anthocyanidin synthase gene in Forsythia $\times$ intermedia reveals organ-specific expression during flower development. Plant Sci. 149: 73-79.

Saito, K., M. Kobayashi, Z. Gong, Y. Tanaka and M. Yamazaki.
1999. Direct evidence for anthocyanidin synthase as a 2oxoglutarate-dependent oxygenase: molecular cloning and functional expression of cDNA from a red forma of Perilla frutescens. Plant J. 17: 181-190.

Saitou, N. and M. Nei. 1987. The neighbor-joining method: a new method for reconstructing phylogenetic trees. Mol. Biol. Evol. 4: 406-425.

Schwinn, K. E. and K. M. Davies. 2004. Flavonoid. p. 92-149. In: K. M. Davies (ed.). Plant pigment and their manipulation. Blackwell Publishing Ltd, Oxford.

Shimizu-Yumoto, H. and K. Ichimura. 2010. Postharvest physiology and technology of cut Eustoma flowers. J. Japan. Soc. Hort. Sci. 79: 227-238.

Sparvoli, F., C. Martin, A. Scienza, G. Gavazzi and C. Tonelli. 1994. Cloning and molecular analysis of structural genes involved in flavonoid and stilbene biosynthesis in grape (Vitis vinifera L.). Plant Mol. Biol. 24: 743-755.

Spelt, C., F. Quattrocchio, J. N. M. Mol and R. Koes. 2000. anthocyaninl of petunia encodes a basic helix-loop-helix protein that directly activates transcription of structural anthocyanin genes. Plant Cell 12: 1619-1631.

Thompson J. D., D. G. Higgins and T. J. Gibson. 1994. CLUSTALW: improving the sensitivity of progressive multiple sequence alignment through sequence weighting, position-specific gap penalties and weight matrix choice. Nucl. Acids Res. 22: 4673-4680.

Uddin, A. F. M. J., F. Hashimoto, M. Kaketani, K. Shimizu and Y. Sakata. 2001. Analysis of light and sucrose potencies on petal coloration and pigmentation of lisianthus cultivar (in vitro). Sci. Hortic. 89: 73-82.

Uddin, A. F. M. J., F. Hashimoto, S. Nishimoto, K. Shimizu and Y. Sakata. 2002. Flower growth, coloration and petal pigmentation in four lisianthus cultivars. J. Japan. Soc. Hort. Sci. 71: 40-47.

Weiss, D., A. H. van der Luit, J. T. M. Kroon, J. N. M. Mol and J. M. Kooter. 1993. The Petunia homolog of the Antirrhinum majus candi and Zea mays A2 flavonoid genes; homolog to flavanone 3-hydroxylase and ethylene forming enzyme. Plant Mol. Biol. 22: 893-897.

Wilmouth, C., J. J. Turnbull, R. W. D. Welford, I. J. Clifton, A. G. Prescott and C. J. Schofield. 2002. Structure and mechanism of anthocyanidin synthase from Arabidopsis thaliana. Structure 10: 93-103. 